Status Report 2016-2019

\title{
Earthquake Monitoring in India
}

\author{
RAJESH PRAKASH ${ }^{1}$, G SURESH ${ }^{1}$ and V K GAHALAUT ${ }^{1,2, *}$ \\ ${ }^{I}$ National Center for Seismology, New Delhi, India \\ ${ }^{2}$ CSIR-National Geophysical Research Institute, Hyderabad, India
}

(Received on 01 August 2019; Accepted on 15 August 2019)

\begin{abstract}
Earthquake monitoring for seismological research and in India started as early as 1898 with the installation of the first seismological observatory at Alipore, Kolkata. Since then, with the worldwide development of earthquake monitoring seismographs, the Indian national seismological network has expanded, and currently, there are 115 observatories, excluding several observatories installed by other research and academic institutes for their specific research programs. These state of the art observatories are equipped with real-time data connectivity which feeds data to auto-location software at the headquarter of the National Center for Seismology, New Delhi. The earthquake information is disseminated to the public, and all stakeholders in real-time and the data are supplied to all scientists for their research purposes. Under a digitization program, all the old analog records of historical earthquakes have been digitized and are archived.
\end{abstract}

Keywords: Earthquakes; Seismology; Earthquake Monitoring

\section{Introduction}

Earthquakes are considered as one of the most dreaded natural hazards over the globe. It is manifested as ground shaking or vibration of the earth caused by the passage of radiated seismic energy generated by a sudden slip on a fault or volcanic activity. The majority of the earthquakes occur due to tectonic activity, particularly the larger ones. The earth's surface consists of twelve major tectonic plates that are in constant motion concerning each other, and their interaction causes stress along their boundaries. The motion at the boundary could be of stick and slip type or aseismic. When the stress level across a fault or the plate boundary reaches its critical value after remaining locked and accumulating strain, sudden slip takes place, resulting in the release of strain energy causing an earthquake. The extent of ground shaking is related to the release of strain energy, the extent of fault which ruptured during the earthquake, and the depth of earthquake source beneath the ground. The ground-shaking, due to an earthquake, poses a hazard. A building will survive if it can withstand ground shaking. The impact of ground shaking may cause partial/total collapse of built environments, cracks on the ground, soil liquefaction and landslides etc. depending on ground conditions and soil characteristics. So it's mainly the collapse of buildings which cause injuries and deaths of human and animal lives, though other processes may also result in loss of lives. Thus it is not the earthquakes that kill people; it is the structures and that too the poorly built structures which kill people. The causalities due to earthquakes over the globe are significant as compared to other natural disasters. A list of ten most dreaded world earthquakes is given in Table 1. A list of dreaded earthquake in India is given in Table 2.

Seismology is a relatively young science. Our understanding about the earthquakes and their occurrence processes improved only after the formulation of the theory of Plate tectonics in the 1960 s, the basic tenet of earthquake occurrence processes, although the Hook's Law was conceived in 1660, and the foundation of modern elasticity theory was completed by Cauchy and Poisson in early decades of nineteenth-century (Lowrie, 2007).

As on date, there is no scientific technique to predict/forecast the occurrence of an earthquake with

*Author for Correspondence: E-mail:vkgahalaut@yahoo.com 
Table 1: Top ten large earthquakes of the world

\begin{tabular}{lll}
\hline Date & Earthquake & Magnitude \\
\hline May 22, 1960 & 1960 Valdivia earthquake & $9.4-9.6$ \\
March 27, 1964 & 1964 Alaska earthquake & 9.2 \\
December 26, 2004 & 2004 Indian Ocean earthquake & $9.1-9.3$ \\
March 11, 2011 & 2011 Tohoku earthquake & 9.1 \\
November 4, 1952 & 1952 Kamchatka earthquakes & 9.0 \\
August 13, 1868 & 1868 Arica earthquake & $8.5-9.0$ \\
January 26, 1700 & 1700 Cascadia earthquake & $8.7-9.2$ \\
April 2, 1762 & 1762 Arakan earthquake & 8.8 \\
November 25, 1833 & 1833 Sumatra earthquake & 8.8 \\
January 31, 1906 & 1906 Ecuador-Colombia & 8.8 \\
& earthquake & \\
\hline
\end{tabular}

brought us to a stage where we can live relatively safely with earthquakes. The derived products/ guidelines for the construction of earthquake-resistant structures required to be adopted with care. The responsibilities lie with the stakeholders. These guidelines are based on past earthquake records and other parameters. These data sets need to be updated for review in existing guidelines for their amendments if so required. The establishment and maintenance of an earthquake monitoring network is the foremost requirement to deal with earthquake hazards.

A real-time seismic network serves two purposes. First, in the detection and location of an earthquake in the minimum possible time and dissemination of earthquake parameters to designated

Table 2: Earthquakes in India with large magnitude and/or large fatalities

\begin{tabular}{|c|c|c|c|}
\hline Date & Location & Mag. & Deaths \\
\hline $2015-04-25$ & Gorkha, Nepal & $7.8 \mathrm{Mw}$ & 8,964 \\
\hline $2005-10-08$ & Kashmir & 7.6 Mw & $86,000-87,351$ \\
\hline $2004-12-26$ & off northern Sumatra & 9.1-9.3 Mw & 227,898 \\
\hline $2001-01-26$ & Bhuj, Gujarat & $7.7 \mathrm{Mw}$ & $13,805-20,023$ \\
\hline 1999-03-29 & Chamoli, Uttarakhand & $6.8 \mathrm{Mw}$ & $\sim 103$ \\
\hline 1993-09-30 & Latur, Maharashtra & $6.2 \mathrm{Mw}$ & 9,748 \\
\hline 1991-10-20 & Uttarkashi, Uttarakhand & $6.8 \mathrm{Mw}$ & $768-2,000$ \\
\hline 1988-08-21 & Udayapur, Nepal & $6.9 \mathrm{Mw}$ & $709-1,450$ \\
\hline $1967-12-11$ & Koyna, Maharashtra & $6.6 \mathrm{Mw}$ & $177-180$ \\
\hline $1950-08-15$ & Assam, Tibet & $8.6 \mathrm{Mw}$ & $1,500-3,300$ \\
\hline $1941-06-26$ & Andaman Islands & 7.7-8.1 Mw & 8,000 \\
\hline $1935-05-31$ & Quetta, Baluchistan & $7.7 \mathrm{Mw}$ & $30,000-60,000$ \\
\hline 1934-01-15 & Nepal-Bihar & $8.0 \mathrm{Mw}$ & $6,000-10,700$ \\
\hline 1905-04-04 & Kangra & $7.8 \mathrm{Ms}$ & $>20,000$ \\
\hline $1897-06-12$ & Shillong, India & $8.0 \mathrm{Mw}$ & 1,542 \\
\hline $1881-12-31$ & Nicobar Islands & $7.9 \mathrm{Mw}$ & \\
\hline $1869-01-10$ & Assam, Cachar & $7.4 \mathrm{Mw}$ & 2 \\
\hline $1833-08-26$ & Kathmandu, Nepal & $8.0 \mathrm{Ms}$ & \\
\hline 1819-06-16 & Allah Bund, Kachchh, Gujarat & 7.7-8.2 Mw & $>1,543$ \\
\hline $1505-06-06$ & Saldang, Karnali zone (S Tibet, Nepal) & $8.2-8.8$ & 6,000 \\
\hline
\end{tabular}

a precise degree of accuracy concerning space, time, and magnitude. Furthermore, it cannot be stopped or prevented from occurrence. However, the improved instrumentation and our improved understanding have authorities for remedial actions if so required. The earthquake data are fundamental to seismology. The seismic monitoring networks are also used in monitoring nuclear explosions, which is a significant 
task of CTBTO. The earthquake data so generated are compiled over time and are used in earthquake hazard assessment and study of earth interior. The earthquake data are also used in various other activities like mineral explorations, site selection of specific constructions like dams or nuclear power plant etc.

Understanding the earthquake process, earth interior and related studies require earthquake data over the globe. This was understood by the world community, and several collective programs for global earthquake monitoring were initiated. It all started with the setting up of the World Wide Standardized Seismic Network (WWSSN) in 1960 by the U. S. Geological Survey. Today we have two Global Seismic Networks (GSN). One,the GSN itself which is established and maintained by United States Geological Survey (USGS), and the other, GEOFON, operated by Geo Forschungs Zentrum (GFZ), Potsdam, Germany.

Besides these broad networks, individual countries also maintain seismic stations network for earthquake monitoring in their country vis-a-vis seismological and hazard related studies. India also operates and maintains a countrywide National Seismic Network for this purpose besides projectbased site-specific networks maintained and operated by various research and academic institutions, e.g., CSIR-National Geophysical Research Institute, Hyderabad; Wadia Institute of Himalayan Geology, Dehradun; Institute of Seismological Research, Gandhinagar, etc.The introduction of VSAT communication in real-time monitoring of earthquake activities in the country brought a remarkable upgradation in data processing and reporting of earthquake parameters (Dattatrayam et al., 2014).

\section{Global Seismological Networks}

The global seismic network GEOFON, maintained by Geo Forschungs Zentrum (GFZ) Germany, was established in1993, dedicated to Ernst von RebeurPaschwitz, the proposer of a global earthquake monitoring, after recording of fist teleseismic earthquake in Potsdam in 1889. The GEOFON global network is operated jointly by more than 50 international partners, and it consisted of about 80 seismological stations spread over all continents, having seismic stations concentration more in Europe and the Mediterranean region as well as in the Indian
Ocean (Fig. 1). All the stations are equipped with broadband seismograph systems, capable of recording high frequency local as well as low frequency large global earthquakes (https://geofon.gfz-potsdam). This network is contributing a leading role in global realtime earthquake monitoring and providing ground motion digital data for almost all fundamental and applied global/regional seismological research projects at GFZ and to the global seismological community.

The GSN, operated and maintained by USGS, is a permanent digital seismic network having more than 150 digital modern seismograph stations spread over 80 countries from the south pole to Siberia and from the Pacific basin to the southern tip of Africa (Fig. 2). It came into existence in 1986 with the cooperation of USGS, the National Science Foundation (NSF), and the Incorporated Research Intuitions for Seismology (IRIS, a university consortium). It is a multiphase scientific facility and societal resource for monitoring, research, and education. The GSN stations consisted of very broadband, high-dynamic range seismometers that measure the vibration of the earth. These instruments are capable of detecting the response of the Earth to the motion of the Sun and the Moon as well as strong shaking near large earthquakes with periods less than a tenth of a second with high fidelity (http://earthqauke.usgs.gov/ monitoring/gsn/). These stations are equipped with an advanced communication system to transmit continuous digital data from the stations to collection points in the U.S. Earthquake monitoring over the globe is an essential activity to the mission of the USGS. The GSN data are freely available to the public and scientists over the world. GSN plays a major role in the operation of the National Oceanic and Atmospheric Administration (NOAA) Tsunami Warning Centers in Hawaii and Alaska. Also, more than 50 stations of the GSN are used for the International Monitoring System of the Comprehensive Test Ban Treaty Organization (CTBTO), towards monitoring of nuclear tests.

\section{Earthquake Monitoring and Data Collection in India}

The National Centre for Seismology (NCS) as an attached office of the Ministry of Earth Sciences, is the nodal agency of the Government of India for earthquake monitoring and related matters in the 


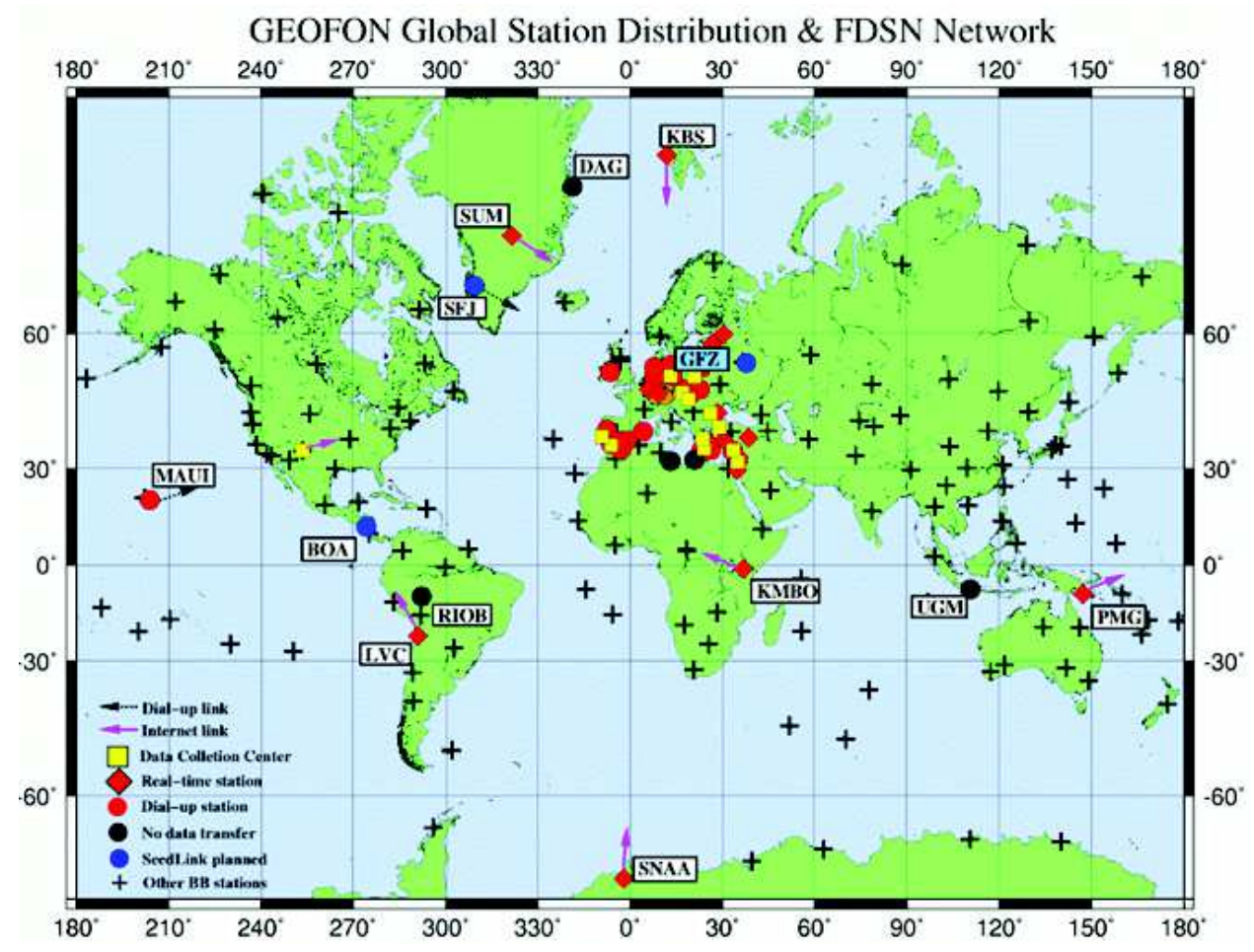

Fig. 1: Worldwide GEOFON Network

country. It was established in 2014 by reorganizing related seismological activities of India Meteorological Department (IMD), the then nodal agency of the Government of India and the Ministry of Earth Science.

Before 1990, the national/Indian seismological network consisted of a conventional type of seismograph systems viz., analog type (photographic/ smoke/ink) recording systems with a short period and long period sensors to record the near and distant events separately. The development of earthquake monitoring network/system in India may be categorized in four phases: Pre-instrumental era (before 1900), Early-instrumental era (1900-1963), Moderninstrumental era (1964-1995) and Digital-instrumental era (1996 onwards). The first observatory was set up in 1898 at Alipore in Kolkata, and the existing network consisted of 115 state-of-art seismic observatories with communication and auto-location facilities. A brief description of the pre-digital era and detailed discussion development of the seismic network in the digital era will be described in this article.

\section{Earthquake Monitoring in Pre-digital Era}

The first seismological observatory was set up by IMD at Kolkata in 1898 after the great Shillong plateau earthquake of 1897 . India suffered from damaging earthquakes of Kangra (1905), Bihar-Nepal (1935), and Assam (1950). But the seismic network strength growth was very slow (five by 1947, eight by 1950 and fifteen by 1960) and this period was the Earlyinstrumental era. The occurrence of 1967 Koyna, 1988 Bihar-Nepal, and 1991 Uttarkashi earthquakes and the global move of the setting of WWSSN in 1960 , strengthened the national network to forty-five observatories by 1980 and further four stand-alone digital systems were established in 1991. This period may be earmarked as a Modern-instrumental era.

\section{Earthquake Monitoring in the Digital Era}

The occurrence of devastating Latur earthquake in 1993 in the stable continental region lead to several initiatives with the help of the World Bank assisted project. As a part of the project, 24 analog observatories mostly in peninsular India, were upgraded with GSN (Global Seismograph Network) standard, state-of-the-art, digital broadband 


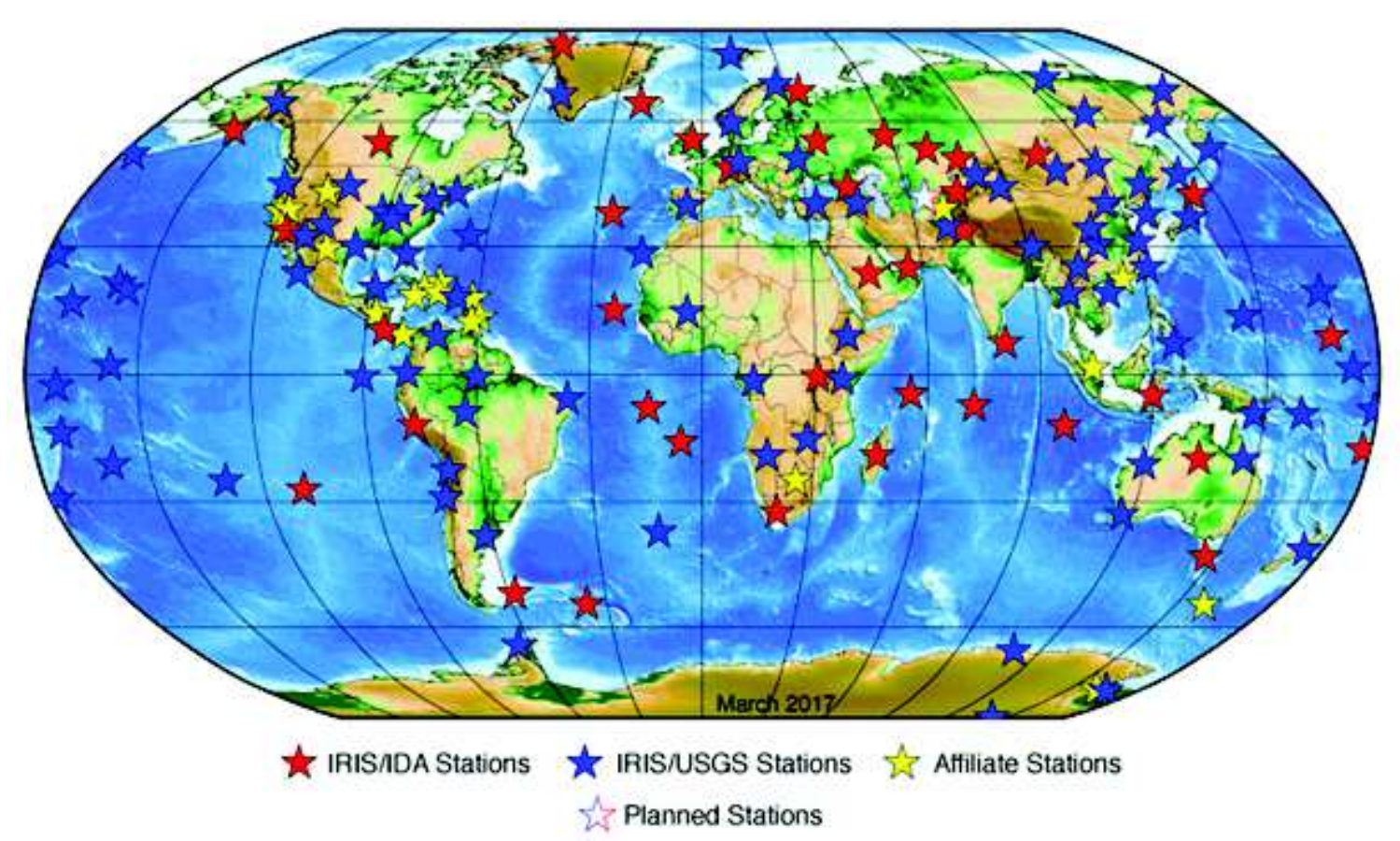

Fig. 2: Worldwide GSN network

seismograph systems during 1996 to 2000 with telephone dial-up for data transmission and interactive mode of processing of earthquake waveform data started with the installation of SEISNET and SEISAN analysis software in 2000-2001 (Bhattacharya and Dattatrayam 2000; Srivastav et al. 2003; Dattatrayam et al. 2014). A Central Receiving Station (CRS) and a National Seismological Database Center (NSDC) were set up at IMD headquarters in New Delhi during 1998 to cater to the needs of near real-time monitoring of seismic activity in and around the country and systematic archival of earthquake data generated by the upgraded observatories (Srivastav et al., 2003). In near real-time mode, the CRS monitored every half-an-hour the seismological observatories equipped with GSN standard seismograph systems, for trigger information. In case a significant trigger, waveform data from observatories close to the expected location were downloaded and analyzed to estimate the source parameters of the earthquakes. Phase data from other observatories equipped with analog seismographs were also obtained through telephone and used in the determination of source parameters. A Preliminary Earthquake Report (PER), containing preliminary information on the origin time, latitude \& longitude of epicenter and magnitude, was then prepared and disseminated to concerned Central and State
Government authorities concerned with emergency response, public information channels and other users. Efforts were made to disseminate the earthquake information at the earliest possible, and usually, it takes about 15-30 minutes depending upon the location and magnitude of the event which was about more than an hour before 1996 (Srivastav et al., 2003). With this, the digital era in seismological observation started in India. The national network consisted of 57 seismic observatories which included 03 observatories in and around Delhi, 03 in Jammu \& Kashmir and 06 in Punjab and Himachal Pradesh for river-valley projects.

By the end of the $20^{\text {th }}$ century, the Seismology division of IMD had grown into a national center of excellence, recognized as National Seismological Center (NSC) (Srivastav et al., 2003). Apart from fulfilling its operational responsibilities, the Center made significant contributions in several new projects initiated by the Government of India, including seismic microzonation and establishment of Earthquake Risk Evaluation Center (EREC) (Srivastav et al. 2003).

The existing national seismological network was non-uniform and had large spatial gaps in several areas. The issue of magnitude threshold of locating earthquakes and the efficacy of the existing national 
seismological network were debated time and again by several committees (viz., Tandon Committee, 1971; Chaudhury Committee, 1986; Arya Committee, 1987, etc.) and the consensus view was that there is a need to strengthen and upgrade the existing seismological network with state-of-the-art equipment in a phased manner to improve the detection and location capabilities. This lead to the design of an optimum seismological network for detecting and locating earthquakes down to magnitude 3.0 in India (Srivastav et al. 2005). Based on $\mathrm{P}$-wave attenuation characteristics of the Himalaya and Peninsular region based on existing earthquake waveform record and theoretical simulation of network response, the optimum network covering the mainland and to some extent, the island regions of Andaman-Nicobar and Lakshadweep, comprising of 177 seismic stations in all was arrived at. The inter-station spacing for Peninsular India was estimated to be of the order of 200-250 km. The corresponding spacing in the tectonically complex Himalayan region with a high degree of lateral heterogeneities was relatively lower, being $100-150 \mathrm{~km}$ along with the primary longitudinal trend and about $50 \mathrm{~km}$ across it. This makes the network density in the Himalayan region more extensive than that in the Peninsular shield. The hypocentral solutions of all the detected earthquakes within the outer boundary of the leading network are expected to have an accuracy of $\pm 2 \mathrm{~km}$ in epicenter and within $\pm 5 \mathrm{~km}$ in focal depth. However, this precision cannot be maintained in respect of sources on the extreme margins of the country and indeed that situated off-shore, where the source location accuracy will degrade to $6-10 \mathrm{~km}$ in epicenter and about $20 \mathrm{~km}$ in focal depth. The task of strengthening the seismological network to the optimum design configuration needs to be implemented in a phased manner by upgrading the existing analog observatories, integrating some of the existing observatories from other organizations, and establishing some new observatories.

Besides, an optimum network for the country, need for separate networks for NCR Delhi (seismic zone-IV; IS:1893, Part 1, 2016) and North East India regions (seismic zone-V; IS:1893, Part 1, 2016) was realized for the study of seismic hazard and corrective measures thereof for safer living of large population and built environment in the region. The occurrence of great Sumatra under-sea earthquake in 2004 triggered an unprecedented tsunami, which severely affected coastal areas of all the Indian Ocean rim countries, raised a demand for urgent setting an early Tsunami Warning Centre. We will discuss the establishment of these networks in subsequent sections.

\section{Seismic Telemetry Network in and Around Delhi (DSTN)}

The first major earthquake reported from Delhi region causing damage to buildings and loss of lives, occurred on 15th July, 1720 of magnitude 6.5 which was followed by aftershocks (Oldham, 1883). The instrumental monitoring of the earthquake in the Delhi region started much later in December 1960 with the commissioning of an analog seismological observatory at Delhi Ridge by the IMD. This seismological observatory was upgraded to seismographs of the WWSSN standard in 1963 (Bhattacharya and Dattatrayam, 2000). The seismograph station recorded a large number of microtremors during the year 196366 , originating from the area in and around Sonepat. To monitor this spurt of earthquake activity, IMD established three mobile observatories in 1966-1967 at three different places adjoining Delhi. Thus, no permanent and robust digital seismic monitoring network existed in this area until 1996.

Considering the importance of this area and for close and continuous monitoring of seismic activity, in the region, a 16 stations VSAT based digital seismic telemetry network was established by IMD during the period 2000-2001 (Srivastav et al., 2001; Dattatrayam et al., 2014). The network had nine field stations within a radius of $80 \mathrm{Km}$ covering an area of NCR, Delhi and remaining were in a radius varying to 200 to $400 \mathrm{Km}$. The twelve stations were single components and only four were three-component seismograph systems. The analysis of digital data generated by this telemetry network for local earthquakes suggested that the focal depth of the region varies from 5-20Km (Shukla et al. 2002). This network had limitations in accurate focal depth determination of earthquake events as a separation between two stations for accurate focal depth determination should be twice the focal depth at least. Besides, three components data are required for research purposes like active fault delineation, attenuation characteristics and hazard studies etc. For 
the precise location of hypocenter parameters, this network was upgraded by nine more threecomponent seismograph stations. This upgraded network consisted of a state-of-art digital broadband seismograph system with VSAT communication and Seiscomp3 autolocation application software for realtime monitoring of earthquakes in the region. The preliminary earthquake parameters (PER) are dissemination in auto-mode.

\section{North-East Seismic Telemetry Network (NESTN)}

The Northeast region of India is one of the most seismically active regions of the world. This region lies at the junction of the Himalayan arc to the north and Burmese arc to the east. The region has experienced 18 large earthquakes $(M>7)$ during the last hundred years including the great earthquakes of Shillong (1897, M=8.1) and the Assam border (1950, $\mathrm{M}=8.6)$. Besides, several hundred small and microearthquakes have also been recorded in the region and felt locally, creating panic amongst the populace. The high seismicity in the region is attributed to the collision of the Indian and the Eurasian plate to the north and subduction tectonics along with the IndoMyanmar range (IMR) to the east. IMD had only six observatories ( 5 analog and one digital) in this region before 2011. To strengthen the seismic monitoring in the region, a 21 station VSAT based seismic telemetry network with a state-of-art seismograph, was set up by upgrading existing observatories and setting up 15 new observatories covering all the states of NorthEast including Sikkim in 2011 (Shukla et al., 2011). The data acquisition is done in hot standby mode and earthquake detection and location is done auto-mode using SeisCompP3 application software developed by GEOFON, Postdam Germany.

Both these networks not only strengthened the earthquake monitoring and related studies in the regions but also strengthened the national seismological network.

\section{Real-Time Seismic Monitoring Network (RTSMN)}

Consequent upon disastrous tsunami due to 26/12/ 2004 great Sumatra earthquake, a state-of-art Tsunami Warning System along with the Tsunami Early Warning Centre for Indian Ocean region was established by Indian National Centre for Ocean Information Services (INCOIS), Hyderabad (autonomous organization under Ministry of Earth Sciences) in the year 2007-08 (Nayak and Kumar 2008; Dattatrayam et al., 2014). Towards monitoring of tsunamigenic earthquakes in the Bay of Bengal, Arabian sea and in Indian ocean; a 17 station stateof-art Real-Time Seismic Monitoring Network (RTSMN) with VSAT communication system, was established and made operational by IMD in 2008. The Response-Hydra auto-location software, developed by National Earthquake Information Centre (NEIC) and U.S. Geological Survey, is used for preliminary estimates of the earthquake source parameters within a few minutes after the occurrence of an earthquake. This system is also capable of providing moment tensor solutions (CMT/MT) for large magnitude earthquakes $(\mathrm{M}>5.5)$. This was the first real-time operational earthquake monitoring network in the country. The ground motion data generated by this network is provided to Tsunami Warning Centre, INCOIS in real-time mode for their use in the assessment of tsunamigenic earthquake and issue of alert/warning. In addition to RTSMN data, the tsunami warning system also receives ground motion data from international stations of IRIS (Incorporated Research Institutions in Seismology). Also, the real-time waveform data form Port Blair, Shillong and Minicoy stations of RTSMN is being transmitted to the SeedLink server of IRIS, Washington through the internet for sharing with the international community.

\section{National Seismological Network (NSN): Status, Operation and Earthquake Monitoring}

By 2011, the NSN consisted of 82 seismological observatories. Along with the establishment of local networks in Delhi NCR, North-East India, and RTSMN for tsunami warning cause, the development and enhancement of NSN to the target of optimum network was in progress and by Feb. 2018 this target reached to 115 (Fig. 3) state-of-art seismic broadband stations with real-time data reception from field stations to CRS, New Delhi. The ground motion data are processed in real-time with set parameters for triggering/assessment of the occurrence of an earthquake followed by the location of earthquake parameters, which are displayed on the computer screen. The earthquake information is disseminated 


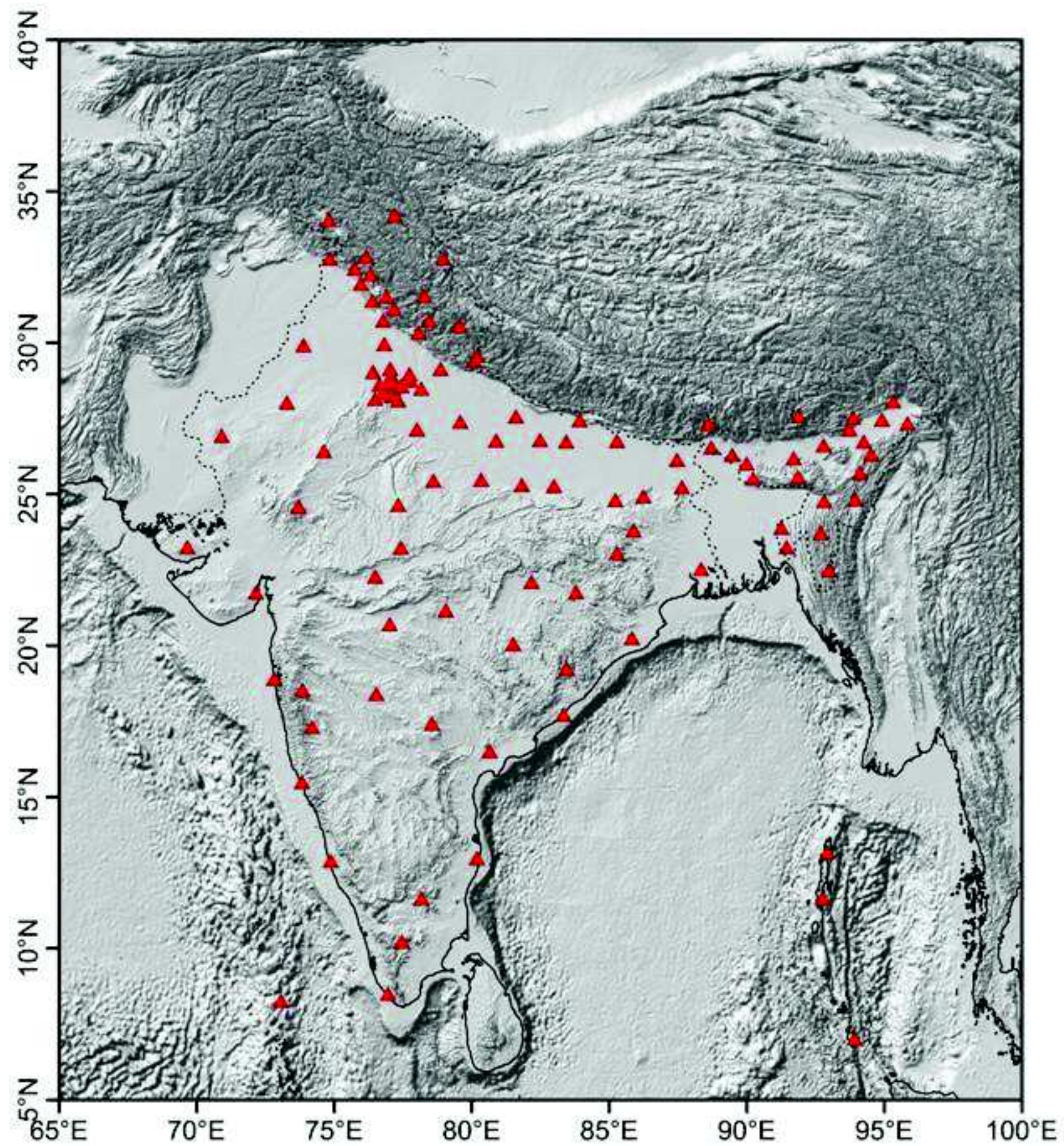

Fig. 3: Indian national seismological network of broadband stations

to the designated destinations. The earthquake parameters are assessed by an scientist in operation duty and final earthquake information is disseminated for follow up actions. The response time which was about an hour before 1996 got reduced to less than 10 minutes now and the earthquake location capability increased significantly.

\section{Data Processing and Archival of Digital Data}

The waveform data received from two local networks, RTSMN and remaining stations of NSN, are collected in their respective CRS and sharing for online monitoring of local/regional earthquake activities, processing earthquake location and preparation monthly earthquake catalogs. The raw data is archived 
in native formats of seismograph systems and standard mini SEED format. The provision also exists for retrieving data of any selected event in SEISAN format. The seismological data from the network stations is compiled, processed, analyzed and archived systematically at the National Seismological Database Centre (NSDC) regularly.

In 2013, NCS and INCOIS implemented a project for setting up VSAT/terrestrial link to seismic and GPS networks stations operated by various agencies and a state-of-art Data Centre was established in NCS comprising of 20 Intel Servers and two storage systems of $50 \mathrm{~TB}$ each for online and offline processing of incoming waveform data from about 170 seismic 60 GPS stations which are operated by various researchers. The data collected at NCS is online replicated to INCOIS over MPLSVPN Link and vice versa. The data center has capabilities such as storing continuous wave form data in standard SEED format, retrieval as per user criteria, SeedLink protocol for connectivity with auto-location software etc. The Data Centre has a web portal (http:/ /www.isgn.gov.in), which gives access to the registered users for downloading the waveform data for research purposes. Fig. 4 shows the earthquakes since 1505 .

\section{Analog Seismogram and Digitization}

In the archive of NCS/IMD, there is a large number of analog seismograms from the period 1965 onwards until the start of the digital era. These seismograms contain a round-the-clock record of short period/long-

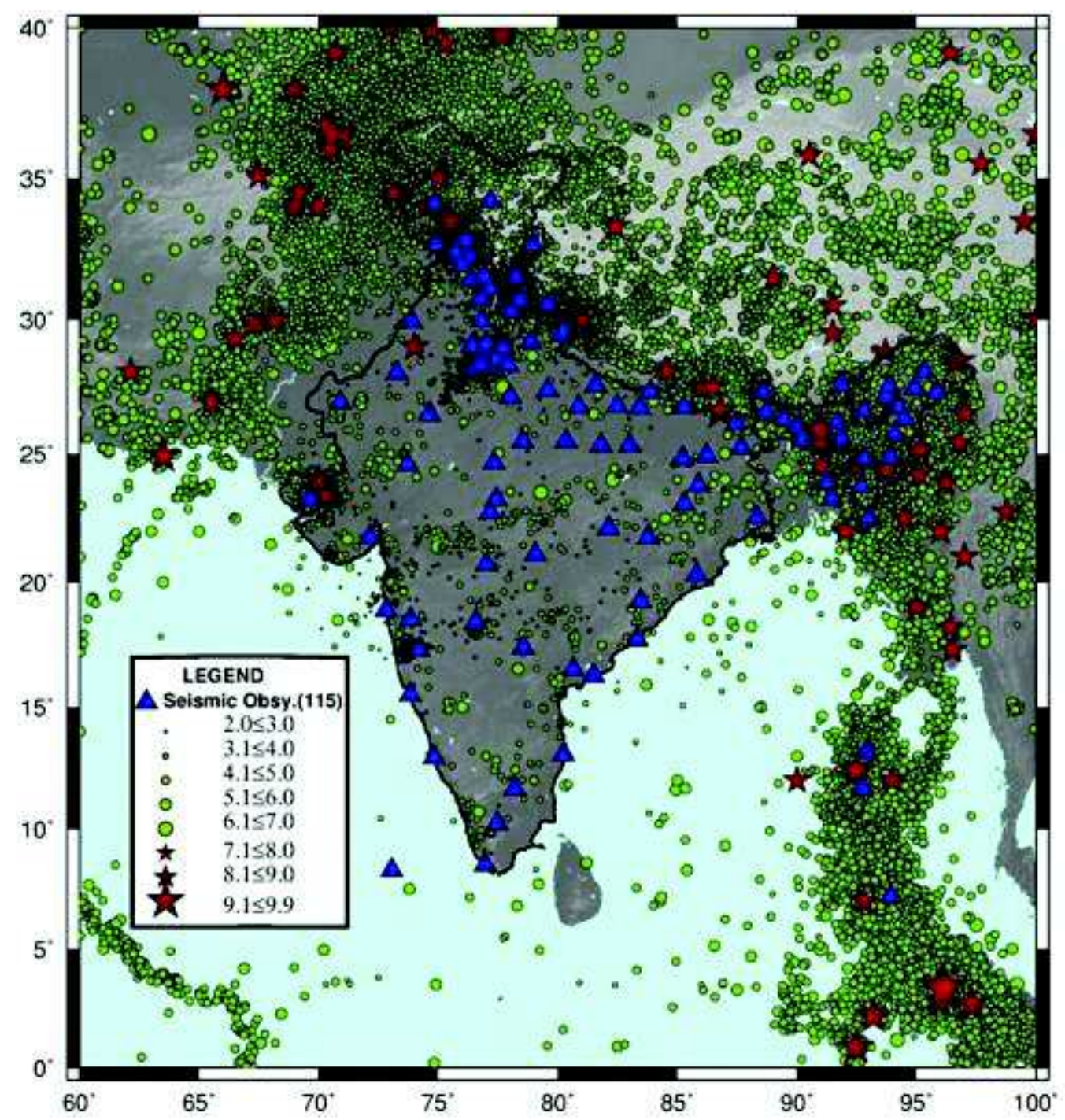

Fig. 4: Earthquakes since 1505 along with the national seismological network 
period ground motion histories made on photographic/ heat-sensitive/smoke recording papers. Some of these records started fading due to the aging effects. It was realized to preserve these records especially seismograms of significant/large and historical magnitudes for seismological research studies. A project on digital archival and vector digitization of these seismograms in electronic media taken up at the beginning of the $21^{\text {st }}$ century. 'Teseo,' widely used application software for the digitization of seismograms developed by Instituto Nazionale di Geofiscia e Vulcanologia (INGV), Italy, was used after customization (Dattatrayam et al., 2014). Seismograms were scanned in 600/800 dpi with 256 grayscales and saved in plain TIFF format with file size varying 150-200 MB. The event portion of the seismogram was vector digitized and output waveform files were generated in ASCII and SAC format. A sample of a historical seismogram of the 1956 Anjar earthquake recorded at Poona is shown in Fig. 5. From 2009 to 2014, completed raster scanning of 100,000 seismic analog charts and vector digitization of 5000 significant earthquake events for long term preservation of seismic analog charts in electronic

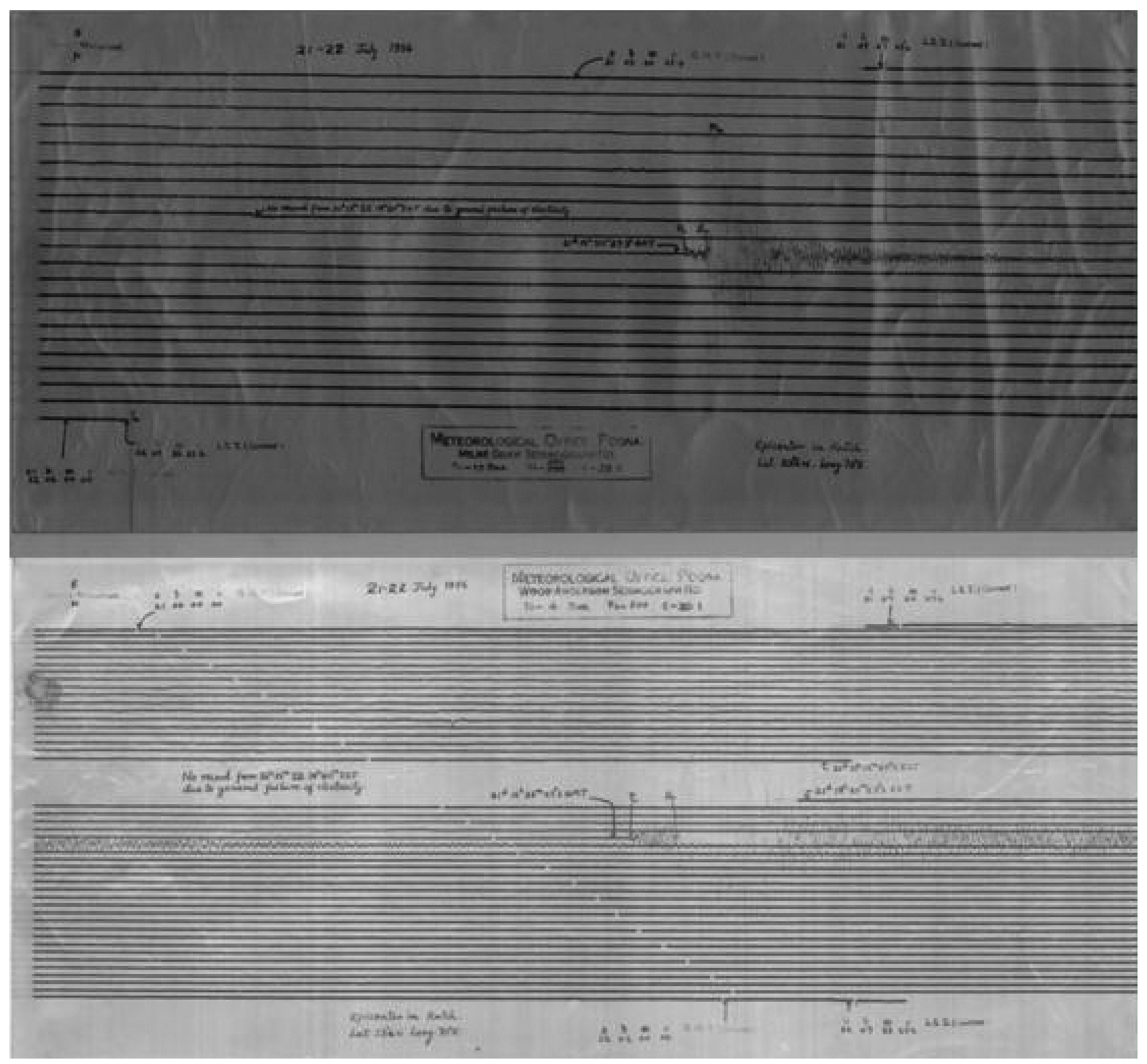

Fig. 5: N-S and E-W components of 1956 Anjar earthquake seismograms at Poona at Milne Shaw and Wood-Anderson seismographs, respectively 
media for use by the research community.

\section{Monthly Seismological Bulletin and Earthquake Catalogues}

The earthquake event generated during PER is further updated with other stations data based on local/ regional/teleseismic events, and phase data are further refined and finalized using the appropriate velocity model. These event databases are compiled monthly as 'Monthly Seismological Bulletins.' These bulletins contain information about different phase arrival times at stations, RMS in the location of earthquake parameters in standard Nordic format. These bulletins are archived in the NCS database and are also sent to International Seismological Center (ISC), UK, regularly as per the fixed schedule for their incorporation in the ISC's Seismological Bulletins, containing data of all global stations. These data may be accessed on www.isc.ac.uk. NCS is a permanent member of ISC since its inception.

The earthquake catalog contains information on origin time/date, latitude and longitude of the epicenter, focal depth, magnitude etc. It is the basic data for seismic hazard assessment of a given region. The first catalog for India and its neighborhood from the earliest time to 1869 was prepared by Oldham (1883). After reassessing the earthquakes information available, a more precise earthquake catalog for magnitudes, Ms $>$ 5.0, was prepared for the Indian region for the period upto 1971 (Tandon and Srivastava, 1974). This catalogue formed the basis for the IMD catalogue, maintained and updated periodically. From 1996 onwards, the earthquake detection and location capabilities of IMD/NCS increased progressively with the induction of digital instrumentation and computer-based analysis, resulting in the earthquake catalogue for the Indian region more comprehensive and uniform (Dattatrayam et al., 2014) region wise.

\section{Data Sharing for Scientific and Other Use}

NCS shares all type of seismological data (PER, catalog, earthquake certificate, seismicity reports, seismological bulletins and waveform data) with different users which include Government, SemiGovernment, Public and Private Organizations, various insurance companies, authorities of various Hydroelectric Projects, Thermal Power Projects, Disaster Management authorities, defense authorities, academic and research institutions both national and international etc. The generation of broadband digital waveform data sets created better opportunities for scientists for more refined studies for understanding the physics of earthquake processes in the Indian subcontinent, refining the crust and upper mantle structures, more accurate velocity models and precise location of local earthquakes and more accurate seismic hazard estimates.

\section{Conclusion}

The broadband digital up-gradation of seismograph stations with the VSAT communication system, strengthening of NSN and state-of-art real-time earthquake monitoring in and around the country have improved the operational capabilities of NCS. The NSN has detection and location capabilities in peninsular shield India and in North-East India down to 3.5; around Delhi down to 2.0 and in extra peninsular shield India down to 4.0. The NSN needs to be strengthened with about 50 more stations to meet the requirement of optimum seismological network with uniform detection and location capabilities down to magnitude 3.0.

The digital data generated by these upgraded stations are being archived systematically at the National Data Centre, NCS New Delhi, and INCOIS, Hyderabad. The availability of these data to researchers has improved our understanding of the earthquake processes, earth structure and other geodynamic processes. At the same time, these data are extensively being used in designing several critical structures. Almost real-time dissemination of earthquake parameters has helped several agencies in taking proactive measures in case of any severe event. Formulation of building codes for a safer living is another milestone that could only be achieved due to the dedicated earthquake monitoring in the country.

\section{Acknowledgement}

We thank Professors Somnath Dasgupta and D M Banerjee to invite us to write this article. This is CSIRNGRI publication number NGRI/Lib/2019/Pub-74. 


\section{References}

Bhattacharya S N and Dattatrayam R S (2000) Recent advances in seismic instrumentation and data interpretation in India Current Science 79 1347-1358

Dattatrayam RS, Suresh G, Baidya P R, Prakash Rajesh, Gautam J L, Shukla H P and Singh D (2014)Standards and Methodologies of Seismological Data Generation, Processing and Archival \& Guidelines for Data Sharing and Supply Proc Indian Natn Sci Acad 80 679-696

Lowrie W (2007) Fundamentals of Geophysics, 2nd Edition, Cambridge University Press, p.393.

Nayak S, and Srinivasa Kumar T (2008) The first Tsunami Early Warning Centre in the Indian Ocean, Risk Wise, Tudor Rose Publications, 175-177

Oldham T (1883) A catalog of the Indian earthquake from the earliest time to the end of A. D. 1869 Mem Geol Surv India 19 169-215

Shukla A K, Prakash Rajesh, Shukla H P, Gupta H V, Bhattachaya S N and Srivastava S K (2002) Delhi seismic telemetry network and analysis of digital waveform data collected through this network Proc 12th Symp Earthquake Engineering, IIT Roorkee 105-113
Shukla A K, Prakash R, Pandey A P, Singh R K, Mondal H S, Singh D and Baidya P R (2011) Overview of Seismic Hazard \& Mitigation in North East India Region IMD Publication p. 94

Srivastav S K, Bhattacharya S N, Shukla A K, Prakash Rajesh, Shukla H P, Baidya P R and Dua S C (2001) Near real-time seismic monitoring system in and around National Capital Region of Delhi Proc Seismic Hazards 220-229

Srivastav S K, Bhattacharya S N, Gupta H V, Dattatrayam R S, Shukla A K, Baidya P R, Prakash Rajesh, Suresh G, Shukla H P and Ghose A K (2003) Recent developments in seismic monitoring and analysis capabilities in India MemoirsGeological Society of India 231-252

Srivastav S K, Prakash R, Dattatrayam R S, Arora S K, Bansal B K and Bhattacharya S N (2005) Configuration of an optimum seismological network for India Mausam 56 465472

Tandon A N and Srivastava H N (1974) Earthquake occurrence in India, In Earthquake Engineering - Jai Krishna Commemoration Volume Sarita Prakashan, Meerut, India. 